\title{
The Application of High Efficient Fatigue Testing Method on Engineering Machinery Steel
}

\author{
Huan XUE ${ }^{1, a}$, Rui GE ${ }^{1}$, Wen-Jie PENG ${ }^{1}$, Yu-Xi MA ${ }^{1}$, Long YAN ${ }^{1}$ \\ ${ }^{1}$ Research and Development Center of Wuhan Iron and Steel group Corp., Wuhan, 430080, China \\ astonemechanics@163.com
}

Keywords: Engineering Structure Steel, Long-range Control, Time Management, Test Efficiency.

\begin{abstract}
The fatigue performance study of high-strength engineering machinery steel is of great significance, as they often bear the reciprocating cycle load, which prone to fatigue fracture damage. Recently, the requirement of fatigue test of kinds of high grade steel is increasing rapidly. However, the existing traditional fatigue testing technology with low efficiency is relatively backward. This contradiction is increasingly outstanding. This paper presents a remote control technology and some efficient time management methods of fatigue test. The new methods are applied on high strength engineering machinery steel. Results show that these methods can effectively improve the efficiency of fatigue test.
\end{abstract}

\section{Introduction}

Engineering machinery industry is an important part of the modern industry. The high strength structural steel takes an important role in the construction machinery manufacturing. In recent years, the construction machinery industry has developed rapidly, so that the demand of high strength structural steel increases a lot. At the same time the comprehensive performance of this kind of material meets higher requirements. At present, the high strength structural steel can effectively reduce equipment weight and the energy consumption. Therefore, it is currently one of the most popular steel materials most company tries to develop. For a conservative estimate, the consumption of high level structural steel on pump truck boom and crane in China is over 50 thousand tons every year. The market potential is tremendous. Recently, Thermo-Mecllanical Control Process (TMCP) technology has been widely used in high strength steel production, which makes the high strength machinery steel more popular.

Engineering machinery steel often bears the cycling load, which prone to fatigue fracture damage. Therefore, the fatigue performance of high strength engineering steel is one of the most important inspection indexes in the process of engineering machine lightweight [1-3]. According to statistics, about $80 \%$ of the component failure is caused by fatigue, of which is suddenly ruptured and often leads serious loss. Therefore, it is important to study on the fatigue performance of the high strength engineering machinery steel, to improve the service life of the products [4-6].

However, the fatigue test requirements of high strength steel including automotive steel, engineering machinery steel increase a lot. Whereas, the existing technology is relatively backward, the testing efficiency is very low. This contradiction is increasingly outstanding. This paper introduces some high efficient fatigue testing method, including the fatigue test of remote control technology and efficient test time management method. The high efficient fatigue testing methods are applied on high strength engineering steel. The result shows that these methods can effectively improve the efficiency of fatigue test.

\section{The Application of Long-range Remote Control Technology}

Fatigue testing machine is used for investigating the high cycle fatigue performance of metal materials. The testing time is full of randomness and uncertainty. Therefore, during the fatigue test, 
the tester needs to keep observation on the monitor to see if the test is finished. If the sample is fractured or the target load cycle is over, the sample can be changed in time.

Due to the uncertainty destruction in the existing technology, this method has two problems: 1. the researchers need to check the statement of fatigue specimen from time to time, the longtime noise is harm to human body; 2. the real-time monitoring is hard to realize, the sample change delay will decrease test efficiency.

According to the above problems, a long-range remote monitoring method is developed for fatigue test. This remote control system is consists of fatigue experiment equipment, computer, wireless communication devices and wireless communication terminal, shown in figure 1. The First step of control process is starting the fatigue test system. Then establish the communication between wireless devices and terminal to monitor the fatigue test. The system will make a judgment on whether the test is over. If the testing sample is fractured or the target load cycle is over, the wireless communication devices on the testing system will send a notification message to the wireless communication terminal to tell the operator the test is over. If the test is continuing, this control system will keep monitoring the equipment. The described communication between wireless device and wireless terminal is based on short message.

This long-range remote control technology can help the test operator to control the experiment at anywhere, even he is far away from the equipment. In addition, the longtime noise which is harm to human body can be avoided. By in-situ remote monitoring, this technology makes it possible to uninterrupted continuous test, so as to improve the efficiency, save energy and reduce cost. This technology has two innovation points. 1 . Truly unattended test is realized by wireless communication between experimenter and the testing machine. 2. The wireless communication network GSM is mature, stable, wide coverage.

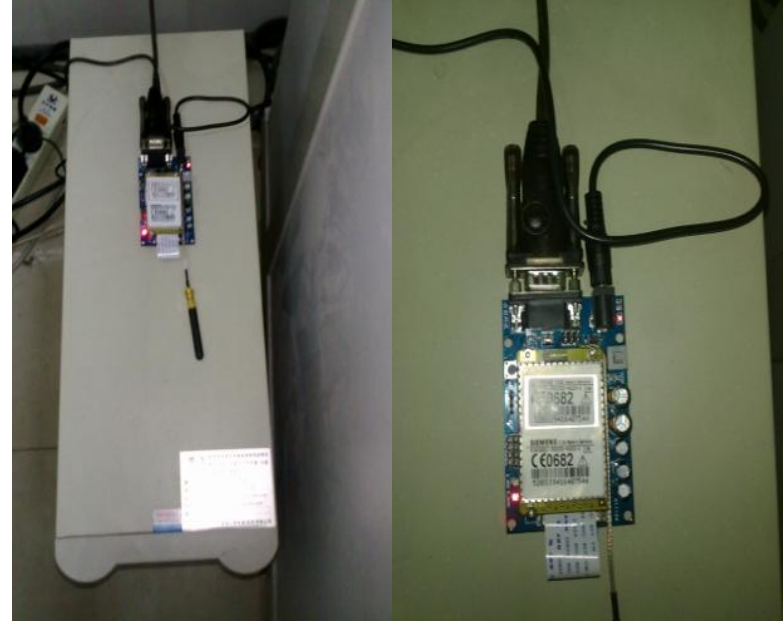

Fig.1 Remote GSM communication module

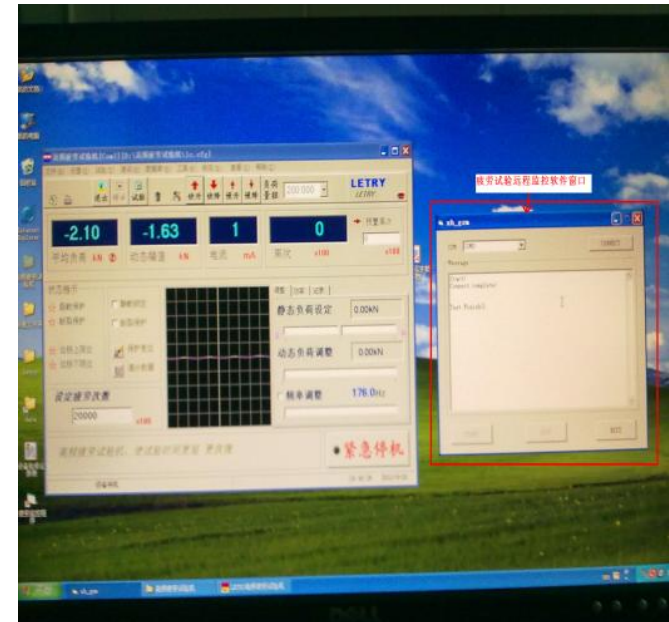

Fig.2 Remote wireless monitoring software

The first step to establish the wireless remote monitoring system on high-frequency fatigue testing machine is check the port on the existing equipment, data transmission lines, and test control software. Prepare the GSM communication module and the serial port switching equipment which is used to transmit data on USB port. The assembled equipment after connection is shown in Figure 1. Remote wireless monitoring software window at run time is shown in Fig.2. When the test starts, choose 'Start monitoring', the stop monitoring window will pop up 'Stop' when the test is over. In addition, the system will send the operator a massage 'Test Finish' through the GSM communication module to made sample change notification.

Before the implementation of this technology, the researchers need every once in a while to check the machine running state. Now the running state of the machine will be monitored by mobile phones, away from the laboratory ultrasonic frequency, noise pollution. And testing machine can be continuing used, the efficiency of test improves nearly $20 \%$. 


\section{The Application of High Efficient Time Managing Method}

To achieve high efficiency of fatigue test, the previous status that all types of products adopt the same testing method must be break out. First of all, classify the test objective of different kinds of products. Different testing scheme should be customized for early developed un-mature product, the new product with or without experienced testing data. For the products with experienced testing data, two dimensional up and down method can be used to enhance the testing efficiency. The up-and-down method is firstly proposed for sensitivity testing by W. J. Dixon and A. M. Mood, and developed by many other experts, which is widely used in fatigue testing [3]. However, the estimates for variance are not exact and the previous data cannot be effectively used in the traditional up-and-down method which leads low test efficiency. The meaning of the two dimensional is that this method takes both the current data and the previous data into account. As the information used in two dimensional up and down method is much larger and more abundant than the traditional one dimensional method, which only cares about the current data. Therefore, the two dimensional method can save many specimens and testing time under the same accuracy requirement. In the other aspect, it can enhance accuracy of the test result with the same number of specimens compares with the traditional one [7-9]. The modified staircase method recommended in the national testing standard GB24176-2009 [10-11] can also improve test efficiency a lot. The initial stress and stress step should be the average fatigue strength and deviation of reference data respectively in the modified staircase method fatigue test.

For the early developed un-mature products, the main purpose is making contrast between the performances of the products, which focuses on the relative fatigue performance between different batches. The test absolute accuracy is not the first aim, so the exploratory research test recommended in national experimental standard can used. The national testing standard GB24176-2009 [10-11] recommends exploratory research requires a minimum of 15 specimens to estimate the mean and the standard deviation of the fatigue strength. Reliability data requires at least 30 specimens. For S-N curve, use a minimum of eight specimens for exploratory testing. It is recommended that two specimens be tested at each of four equally spaced stress levels. For reliability design purposes, however, at least 30 specimens are required. In this case, test six specimens at each of five equally spaced stress levels.

For military products and other steel products which have serious request of fatigue performance, the P-S-N curve should be used instead of the traditional S-N curve. The failure probability of traditional S-N curve is 50\%. Whereas, P-S-N curve can select failure probability according to need. For higher security requirements, the failure probability is recommended to adjust to more than $95 \%$. For the mature new products without reference data, the traditional up and down method and point to point S-N method should be used to obtain a more stable and comprehensive data.

Tab.1 Up and down method test data of engineering machinery steel

\begin{tabular}{|c|c|c|c|c|c|c|c|c|c|c|c|c|c|}
\hline $\begin{array}{c}\mathrm{S}_{\mathrm{a}} \\
(\mathrm{Mpa})\end{array}$ & \multicolumn{10}{|c|}{ Test Sequence } \\
\cline { 2 - 14 } & 1 & 2 & 3 & 4 & 5 & 6 & 7 & 8 & 9 & 10 & 11 & 12 & 13 \\
\hline 263.5 & & & & & & $\mathrm{X}$ & & & & & & & \\
\hline 255 & & & $\mathrm{X}$ & & Pass & & $\mathrm{X}$ & & $\mathrm{X}$ & & & & $\mathrm{X}$ \\
\hline 246.5 & & Pass & & Pass & & & & Pass & & $\mathrm{X}$ & & Pass & \\
\hline 238 & Pass & & & & & & & & & & Pass & & \\
\hline
\end{tabular}




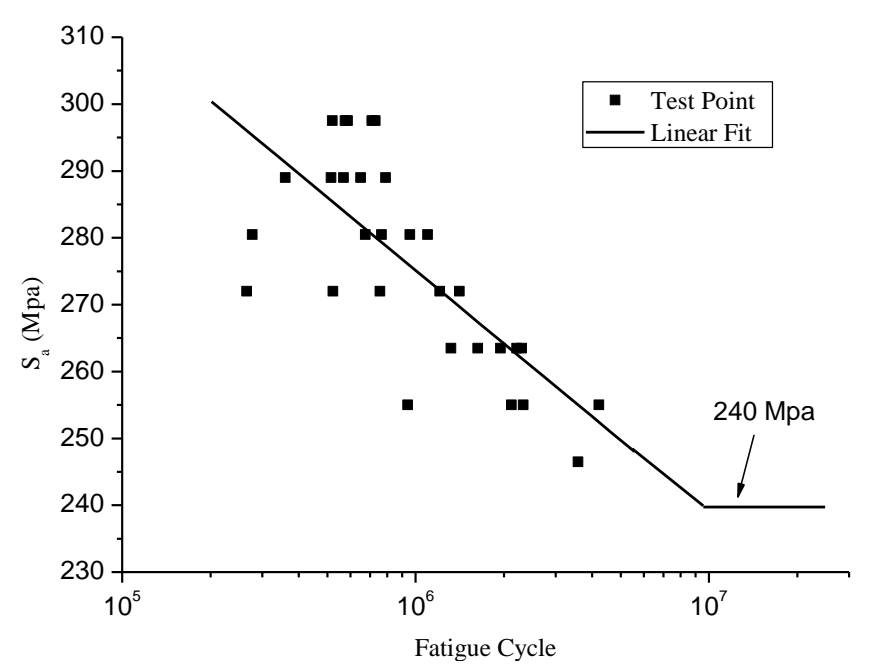

Fig.3 S-N curve of high strength construction machinery steel

The high strength engineering machinery steel is a product with no previous experience data, so the standard up and down method and point to point $\mathrm{S}-\mathrm{N}$ curve experiment is needed. The up and down method test data result is shown in Table 1 . S-N curve of high strength construction machinery steel is shown in Figure 3. In the process of test, appropriate arrangement test order and test time can improve test efficiency. For the low load testing samples, whose loads in the up and down method are under $260 \mathrm{Mpa}$, try to arrange them before off duty time. Thus the sample can continue to run at night, which makes full use of time. For the high load testing samples, whose loads are higher than $280 \mathrm{Mpa}$, which needs to be replaced from time to time, should be arranged at day time. It can make fatigue testing machine nearly non-stop for saturated operation.

\section{Conclusions}

The application of long-range remote control technology can help the test operator to control the experiment at anywhere. By in-situ remote monitoring, this technology makes it possible to uninterrupted continuous test. For the actual situation, if the testing time is 24 hours a day, this technology can save 2-3 average working hours everyday. The test efficiency will be enhanced $8 \%$ to $12 \%$.

After subdividing test classification, nearly half of the fatigue test can improve test efficiency. If the testing time is also 24 hours a day, for early developed un-mature product, using exploratory test instead of reliability test can save at least 6 to 8 hours everyday. For the product with reference data, using two dimensional or modified up and down method instead of traditional one can save 7 to 10 average working hours a day. The test efficiency will be enhanced at least $20 \%$.

The application of high efficient time managing method can save about 2 average working hours a day, which will enhance the test efficiency about $8 \%$.

\section{References}

[1]Z. T. Gao, X. T. Jiang, J. J. Xiong: Fatigue performance experimental design and data processing, Press of Beijing University of Aeronautics and Astronautics.

[2]C. R. Chen: Fatigue and fracture, Press of Huazhong university of science and technology, 2002.

[3]W. J. Dixon, A. M. Mood. A Method for obtaining and analyzing sensitivity data. J Amer Statistical Assoc, 1928, 43, 109-126.

[5]J. Y. Zhang, D. L. Wang. Up and down method for fatigue strength with two details in series. Journal of Experimental Mechanics, 2006, 21(5), 579-583. 
[6]Lin S K,Lee Y L,Lu M W. Evaluation of the staircase and the accelerated test methods for fatigue limit distributions[J].International Journal of Fatigue, 2001, 23(1), 75-83.

[7]H. M. Fu, G. Yin, Two-dimensional up-and-down method. Acta Aeronautica Et Astronautica Sinica 1998, 19 (6), 748-753.

[8]H. M. Fu, G. Yin, A method for determining fatigue limits with small samples. Journal of Mechanical Strength, 1999, 21(2), 115-117.

[9]H. M. Fu, Formulas for tolerance limits and confidence limits of nomal population percentiles and percentages. Acta Aeronautica Et Astronautica Sinica 1994, 15 (1), 94-101.

[10]Chinese National Strandard: Metallic materials Fatigue testing- Axial force controlled method, GB/T3075-2008.

[11]Chinese National Strandard: Metallic materials Fatigue testing Statistical planning and analysis of data, GB/T24176-2009. 